\title{
Prostaglandin-dependent modulation of dopaminergic neurotransmission elicits inflammation-induced aversion in mice
}

\author{
Michael Fritz, ${ }^{1}$ Anna M. Klawonn, ${ }^{1}$ Anna Nilsson, ${ }^{1}$ Anand Kumar Singh, ${ }^{1}$ Joanna Zajdel, ${ }^{1}$ Daniel Björk Wilhelms, ${ }^{1,2}$ \\ Michael Lazarus, ${ }^{3}$ Andreas Löfberg, ${ }^{1}$ Maarit Jaarola, ${ }^{1}$ Unn Örtegren Kugelberg, ${ }^{1}$ Timothy R. Billiar, ${ }^{4}$ David J. Hackam, ${ }^{5}$ \\ Chhinder P. Sodhi, ${ }^{5}$ Matthew D. Breyer, ${ }^{6}$ Johan Jakobsson, ${ }^{7}$ Markus Schwaninger, ${ }^{8}$ Cünther Schütz, ${ }^{9}$ Jan Rodriguez Parkitna, ${ }^{10}$ \\ Clifford B. Saper, ${ }^{11}$ Anders Blomqvist, ${ }^{1}$ and David Engblom ${ }^{1}$ \\ DDepartment of Clinical and Experimental Medicine and 'Department of Emergency Medicine, Linköping University, Linköping, Sweden. ${ }^{3}$ International Institute for Integrative Sleep Medicine, \\ University of Tsukuba, Tsukuba, Japan. ${ }^{4}$ Department of Surgery, University of Pittsburgh Medical Center, Pittsburgh, Pennsylvania, USA. ${ }^{5}$ Department of Surgery, Johns Hopkins University, \\ Baltimore, Maryland, USA. ${ }^{6}$ Biotechnology Discovery Research, Lilly Research Laboratories, Indianapolis, Indiana, USA. ${ }^{7}$ Wallenberg Neuroscience Center and Lund Stem Cell Center, \\ Lund University, Lund, Sweden. ${ }^{8}$ Institute of Experimental and Clinical Pharmacology and Toxicology, University of Lübeck, Lübeck, Germany. ${ }^{9}$ Molecular Biology of the Cell I, \\ German Cancer Research Center, Heidelberg, Germany. ${ }^{10}$ Department of Molecular Neuropharmacology, Institute of Pharmacology of the Polish Academy of Sciences, Krakow, Poland. \\ ${ }^{11}$ Department of Neurology, Beth Israel Deaconess Medical Center and Harvard Medical School Boston, Massachusetts, USA.
}

\begin{abstract}
Systemic inflammation causes malaise and general feelings of discomfort. This fundamental aspect of the sickness response reduces the quality of life for people suffering from chronic inflammatory diseases and is a nuisance during mild infections like common colds or the flu. To investigate how inflammation is perceived as unpleasant and causes negative affect, we used a behavioral test in which mice avoid an environment that they have learned to associate with inflammation-induced discomfort. Using a combination of cell-type-specific gene deletions, pharmacology, and chemogenetics, we found that systemic inflammation triggered aversion through MyD88-dependent activation of the brain endothelium followed by COX1-mediated cerebral prostaglandin $\mathrm{E}_{2}\left(\mathrm{PCE}_{2}\right)$ synthesis. Further, we showed that inflammation-induced PGE $\mathrm{E}_{2}$ targeted EP1 receptors on striatal dopamine D1 receptor-expressing neurons and that this signaling sequence induced aversion through CABA-mediated inhibition of dopaminergic cells. Finally, we demonstrated that inflammation-induced aversion was not an indirect consequence of fever or anorexia but that it constituted an independent inflammatory symptom triggered by a unique molecular mechanism. Collectively, these findings demonstrate that $\mathrm{PCE}_{2}$-mediated modulation of the dopaminergic motivational circuitry is a key mechanism underlying the negative affect induced by inflammation.
\end{abstract}

\section{Introduction}

Upon inflammation, an array of brain-mediated responses occurs. They are collectively referred to as the sickness syndrome and include fever, decreased food intake, inactivity, social withdrawal, and corticosteroid secretion $(1,2)$. These objective symptoms are accompanied by feelings of malaise and discomfort. Several lines of evidence suggest that malaise is not a consequence of the objective responses mentioned above, but is a distinct entity. Thus, several of the symptoms induced by inflammation can also be caused by rewarding stimuli, such as psychostimulants (elevated body temperature, anorexia, and corticosteroid secretion) and opioids (inactivity and social withdrawal) without producing discomfort. In addition to being a nuisance during mild infectious diseases, inflammation-induced malaise is a major cause of reduced quality of life for individuals suffering from chronic inflammatory diseases, such as arthritis, tuberculosis, AIDS, and malaria (3-5).

Authorship note: M. Fritz and A.M. Klawonn contributed equally to this work. Conflict of interest: The authors have declared that no conflict of interest exists. Submitted: July 20, 2015; Accepted: November 12, 2015.

Reference information: / Clin Invest. 2016;126(2):695-705. doi:10.1172/JCI83844.
Further, converging lines of evidence suggest that inflammatory signaling is involved in the pathophysiology of depression (4, 6-8). Despite the strong link between inflammation and negative affect, surprisingly little is known about the underlying molecular mechanisms. Here, we used advanced mouse genetics in combination with behavioral analysis to dissect the signaling pathways underlying acute inflammation-induced malaise and aversion. We demonstrate that the negative affect associated with systemic inflammation is induced by a unique mechanism that is distinct from those eliciting fever and loss of appetite and involves the modulation of dopaminergic motivational circuitry by prostaglandins (PGs) induced via brain endothelial activation.

\section{Results}

Systemic inflammation induces aversion. To assess if inflammation is perceived as something negative and uncomfortable in rodents, we used conditioned place aversion to systemic inflammation (9). We used i.p. injection of bacterial cell wall LPS as inflammatory stimulus, since low doses of LPS have been shown to rapidly induce depressed mood in human subjects $(10,11)$. Conditioned place aversion is widely used as an index of unpleasantness and 
A
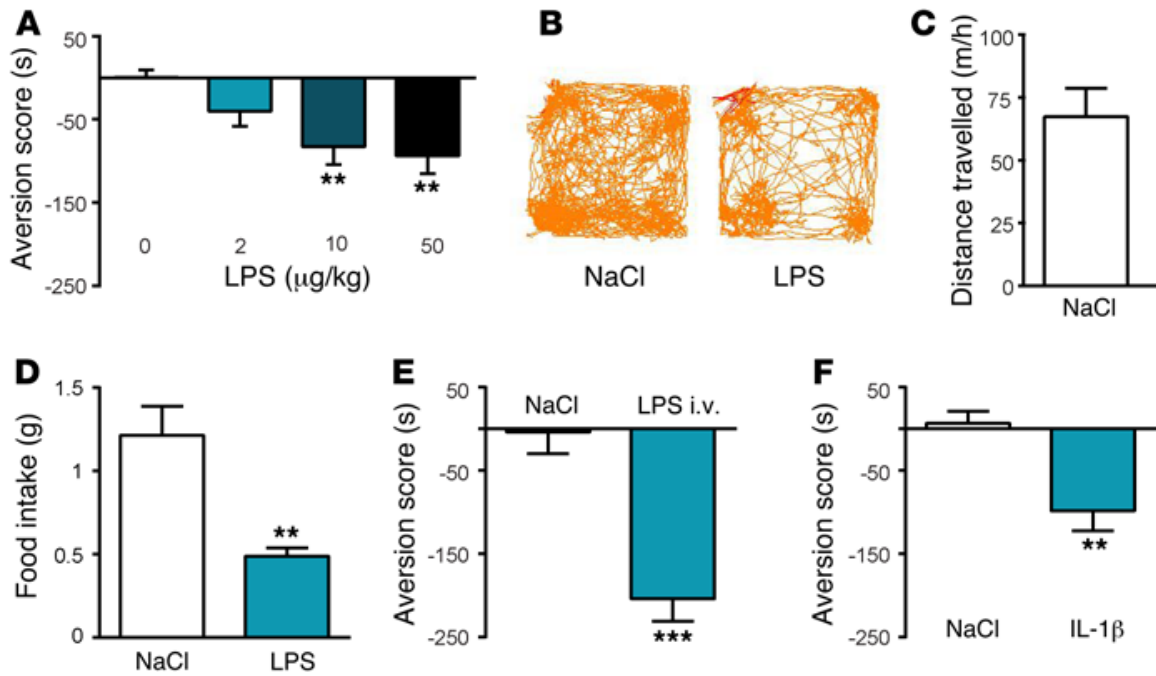

Figure 1. Inflammation induces conditioned place avoidance. (A) Decrease in time spent in the LPS-paired chamber after conditioning with $0,2,10$, and $50 \mu \mathrm{g} / \mathrm{kg}$ LPS i.p. ( $n=9,4,8$, and 9, respectively). Mice develop significant avoidance at concentrations of 10 and $50 \mu \mathrm{g} / \mathrm{kg}$ compared with the saline group. (B) Mouse tracks recorded over 1 hour after either saline or $10 \mu \mathrm{g} / \mathrm{kg}$ LPS i.p. injections. (C and D) Mice significantly decrease their movement, i.e., distance traveled ( $n=10, \mathrm{NaCl} ; 10, \mathrm{LPS})$ (C), and food intake ( $n=7, \mathrm{NaCl} ; 8, \mathrm{LPS})$ (D) after a single injection of $10 \mu \mathrm{g} / \mathrm{kg}$ LPS i.p. (E) i.v. administration of $10 \mu \mathrm{g} / \mathrm{kg}$ LPS induces significant avoidance of the paired chamber, as compared with the chamber paired with saline i.v., ( $n=8, \mathrm{NaCl}$; 8, LPS i.v.). (F) Administration of IL-1 $\beta$ i.p. (600 ng/mouse) also decreased the time mice spent in the conditioning chamber as compared with mice trained with saline $\left(n=6, \mathrm{NaCl}\right.$; 6 , LPS i.p.) ${ }^{*} P<0.05,{ }^{* *} P<0.01,{ }^{* *} P<0.001$, ANOVA followed by Dunnett's post hoc test (A) or Student's $t$ test (C-F).

has been instrumental in identifying the neural circuits behind the affective component of pain (12). Mice were repeatedly injected with LPS i.p. in a chamber with distinctive visual cues and with saline in a visually different chamber. They were then allowed to choose freely between the 2 chambers, and the extent to which they avoided the inflammation-paired chamber was assayed. Mice avoided the LPS-paired chamber even at doses as low as $10 \mu \mathrm{g} /$ $\mathrm{kg}$ (Figure 1A). At this dose, LPS induced robust but mild signs of sickness, including reductions in locomotor activity (Figure 1, B and C) and food intake (Figure 1D). To rule out the possibility that inflammation-induced aversion is only elicited when the inflammation is confined to the peritoneal cavity, we also injected LPS i.v. This also led to aversion (Figure 1E), as did IL-1 $(600 \mathrm{ng} /$ mouse) injections i.p. (Figure $1 \mathrm{~F}$ ), demonstrating that many different forms of inflammation cause aversion.

Involvement of the brain endothelium. As the brain endothelium is an important link in the immune-to-brain signaling underlying some, but not all, symptoms of systemic inflammation (1, 13-16), we investigated whether it mediates inflammation-induced aversion. To introduce deletions specific to the brain endothelial cells, we used Slco1c1 Cre-ER ${ }^{T 2}$ mice (14). We validated the Cre-induced recombination using a reporter line (Figure 2A) and crossed the Cre line with mice with floxed Myd88 alleles. This cross resulted in offspring with $M y d 88$ deletion in the brain endothelium (Myd88 $\Delta$ bEnd). MyD88 is a critical hub for inflammatory signaling induced by IL-1, IL-18, and most TLRs. Myd88 $\Delta$ bEnd mice did not develop aversion to LPS $(10 \mu \mathrm{g} / \mathrm{kg}$; Figure $2 \mathrm{~B})$ or IL-1 $\beta$ (600 ng/mouse; Figure 2C), illustrating that the brain endothelium is a critical interface between the circulation and the brain

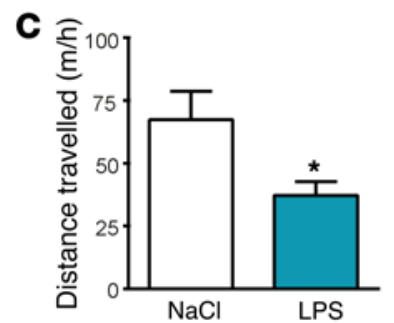

for the aversive signaling of systemic inflammation. In contrast, the deletion of Myd88 in myeloid cells had no effect on LPS-induced aversion (Figure 2D). Interventions against IL-1 signaling, such as administration of an IL-1 receptor (IL-1R) antagonist (Figure 2E), KO of caspase-1 (Figure $2 \mathrm{~F}$ ), or $\mathrm{KO}$ of the IL-1R type 1 (Figure 2G), did not block LPS-induced aversion. Since TNF $\alpha$ signaling, under some circumstances, compensates for IL-1 signaling (17), we next tested if an intervention targeting $\mathrm{TNF} \alpha$ receptors (type 1 and 2), or a combined intervention targeting both $\mathrm{TNF} \alpha$ receptors (type 1) and IL-1Rs, affected LPS-induced aversion. While deletion of TNF $\alpha$ receptors alone had no effect, mice with deletions of both TNF $\alpha$ and IL-1Rs displayed an attenuated aversive response to LPS. Further, deletion of Tlr 4 in the brain endothelium (Tlr4 $\Delta$ bEnd) blocked the LPS-induced aversion (Figure 2H). Collectively, these results indicate that LPS and IL-1 directly bind to brain endothelial cells and induce aversion through MyD88-dependent endothelial activation.

Inflammation-induced aversion is dependent on PG synthesis in the brain. The activated brain endothelium triggers certain inflammatory symptoms through $\mathrm{PGE}_{2}$ synthesis $(1,16,18-20)$. Thus, we next tested if the general cyclooxygenase inhibitor indomethacin attenuated the aversion. Indeed, mice administered indomethacin $(0.3 \mathrm{mg} / \mathrm{kg})$ spent as much time in the LPS-paired chamber after conditioning as before (Figure 3A), demonstrating that the aversion is PG dependent. We next treated mice (i.p.) with a selective COX-1 inhibitor (SC-560; $5 \mathrm{mg} / \mathrm{kg}$ ) or a COX-2-specific inhibitor (parecoxib; $10 \mathrm{mg} / \mathrm{kg}$ ) before the LPS injections. Interestingly, the COX-2-selective inhibitor, which previously has been shown to inhibit inflammation-induced brain responses at the dose used (21), had no effect. In contrast, the COX-1-specific inhibitor completely blocked the aversion (Figure 3A). We achieved similar results using mice lacking $\mathrm{COX}-1$ and $\mathrm{COX}-2$, respectively (Figure 3B). To clarify whether the COX-1 effect was specifically in the brain, we injected a low dose $(1 \mu \mathrm{g})$ of the COX-1 inhibitor SC-560 intracerebroventricularly (i.c.v.). This treatment abolished the aversion completely (Figure 3C). To identify the critical prostanoid species, we used mice lacking microsomal PGE synthase-1 (mPGES-1), the main terminal isomerase responsible for inflammation-induced $\mathrm{PGE}_{2}$ production (22). These mice displayed a blunted aversion (Figure 3D), indicating that $\mathrm{PGE}_{2}$ is an important mediator downstream of COX-1.

The critical role of EP1Rs on striatal dopamine D1R-expressing neurons. To determine which $\mathrm{PGE}_{2}$ receptor drives the inflammatory aversion, we used mice lacking $\mathrm{PGE}_{2}$ receptor subtypes EP1-4. 

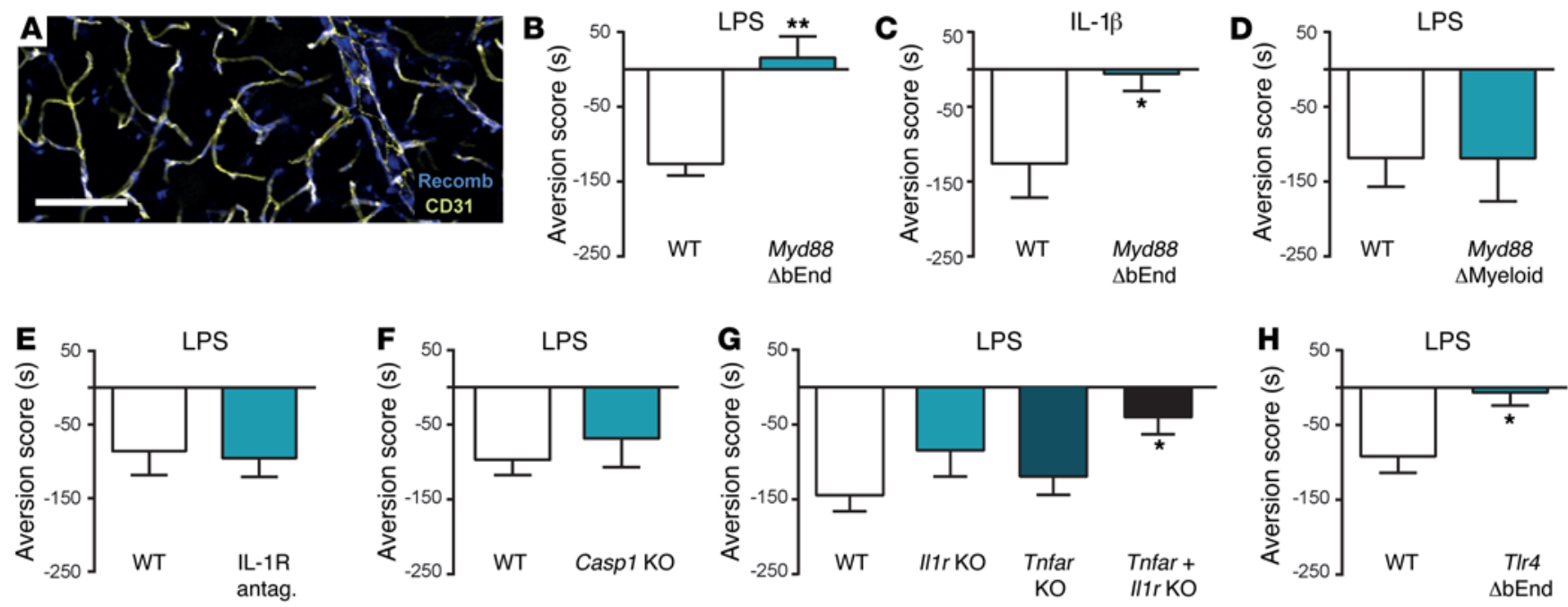

Figure 2. Inflammatory aversion is driven by MyD88-dependent signaling in the brain endothelium. (A) Recombination specific to CD31-positive brain endothelial cells visualized using a reporter line. (B and C) Mice lacking MyD88 in brain endothelial cells (Myd88 $\mathrm{b}$ End) do not demonstrate place aversion

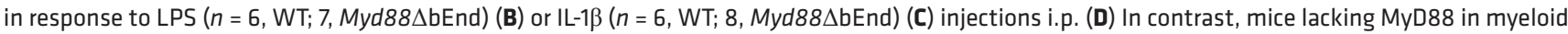
cells display an aversive response to LPS. (E-C) Mice given an IL-1R antagonist i.p. ( $n=6$, WT; 6, IL-1R antagonist; E), mice lacking caspase-1 ( $n=6$, WT; 6 , Casp1 KO; F), and mice lacking IL-1Rs (I/1r KO; $n=13, \mathrm{WT} ; 14$, I/1r KO; G), develop normal avoidance of the chamber paired with LPS injections, as do mice lacking the TNF $\alpha$ receptors 1 and $2(n=7 ; \mathbf{G})$. In contrast, mice lacking both TNF $\alpha$ receptor 1 and the IL-1R display a blunted aversive response $(n=8$; $\mathbf{G})$. (H) Mice with deletion of TLR4 selectively in the brain endothelium (T/r4 $\Delta$ bEnd) do not demonstrate place aversion in response to LPS i.p. ( $n=5$, WT; 5, TIr $4 \Delta$ bEnd). Scale bar: $100 \mu \mathrm{m} .{ }^{*} P<0.05,{ }^{*} P<0.01$, Student's $t$ test (B-F and $\mathbf{H}$ ) or 1-way ANOVA followed by Dunnett's post hoc test (C).

Mice lacking EP1R or EP2R had no or very mild aversions (Figure 3, E and F), whereas mice without EP3Rs or lacking EP4Rs in the brain (Ep4r- $\triangle \mathrm{CNS}$ ) displayed normal aversions in response to LPS (Figure 3, G and H). Since EP1Rs are expressed on dopamine D1Rexpressing neurons in the striatum (23), where they have been suggested to regulate affective functions (24), we investigated the role of EP1Rs further by testing whether inflammatory aversion is mediated by $\mathrm{PGE}_{2}$ binding to EP1Rs on dopamine D1R-expressing neurons. We generated a mouse line in which EP1R expression is blocked but can be rescued in a cell-type-specific manner upon Cre-mediated recombination (Supplemental Figure 1; supplemental material available online with this article; doi:10.1172/

A
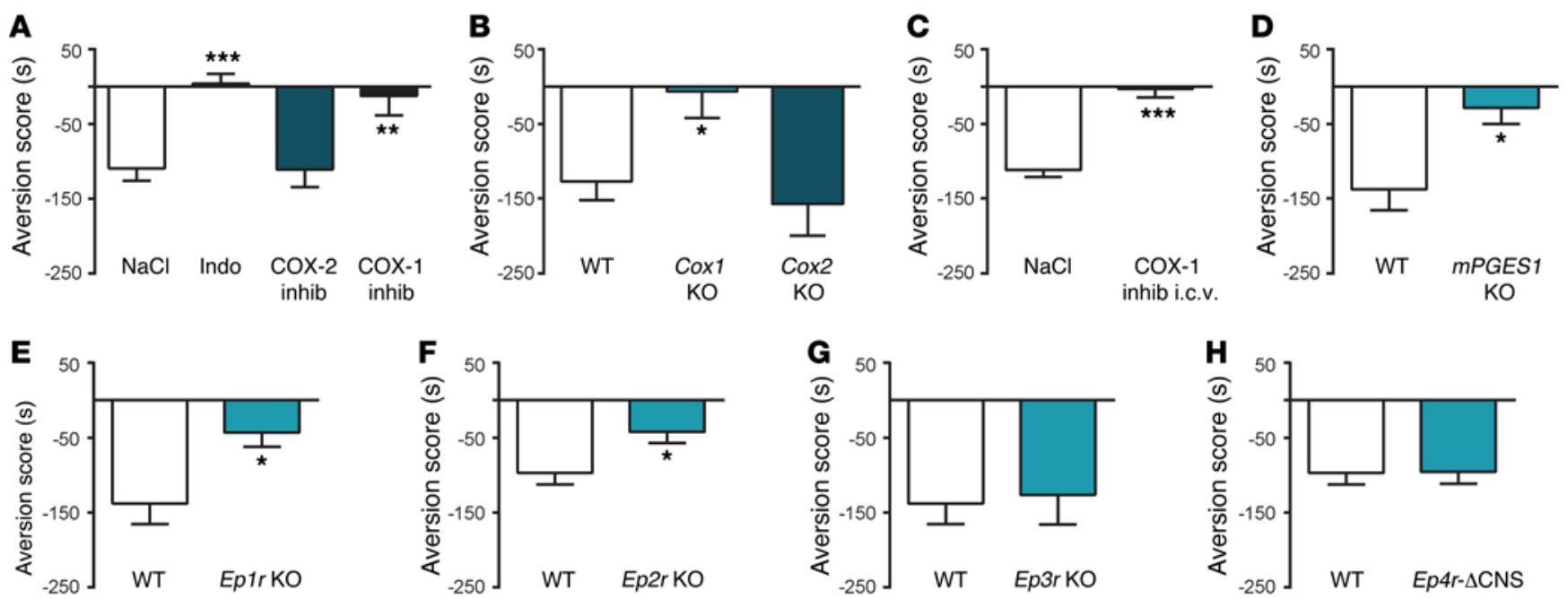

Figure 3. Inflammation-induced aversion is dependent on cerebral $\mathrm{PGE}_{2}$ synthesis. (A) Place avoidance in mice pretreated i.p. with $\mathrm{NaCl}(n=7)$, the unspecific COX inhibitor indomethacin (Indo; $n=8$ ), the COX-2-specific inhibitor parecoxib $(n=5)$, or the COX-1-specific inhibitor SC-560 ( $n=6)$. (B) Aversion in mice lacking COX-1 (Cox1 KO) or COX-2 (Cox2 KO). Aversion is intact in WT mice $(n=6)$ and mice lacking COX-2 $(n=6)$ but blocked in mice lacking COX-1 $(n=8)$. (C) LPS-induced aversion in mice given i.c.v. injections with $\mathrm{NaCl}(n=8)$ or SC-560 $(n=6)$ during conditioning. (D) Mice lacking mPGES-1 ( $m P G E S 1 \mathrm{KO})$ display a significantly reduced avoidance of the LPS-paired chamber as compared with WT mice $(n=7, \mathrm{WT} ; 6, m P C E S 1 \mathrm{KO})$. (E-H) Aversion scores from mice lacking PGE 2 receptors of type EP1-4. Aversion is significantly blunted in mice lacking EP1Rs $(n=7$, WT; 8, Ep1r KO) (E) and EP2Rs $(n=8$, WT; 8, Ep2r KO) (F) but not in mice lacking EP3Rs ( $n=6$, WT; 6, Ep3r KO) (C), or EP4Rs ( $n=8$, WT; 4, Ep4r- $\Delta$ CNS; control group shared with EP2) (H). ${ }^{*} P<0.05,{ }^{* *} P<0.01,{ }^{* *} P<0.001$, ANOVA followed by Dunnett's post hoc test (A and B) or Student's $t$ test (C-H). 

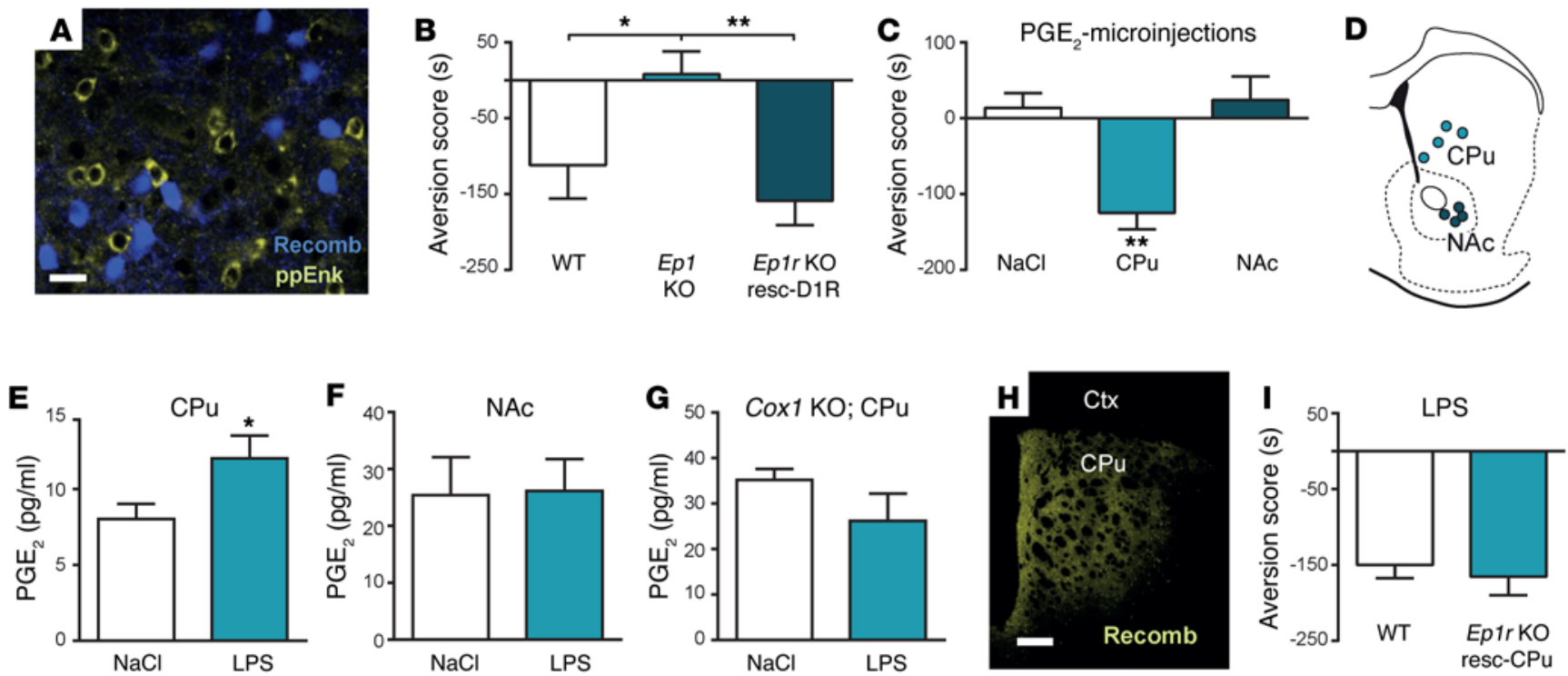

Figure 4. Inflammation-induced aversion is dependent on striatal EP1Rs. (A) Micrograph demonstrating D1R-specific recombination in preproenkephalin-negative (ppEnk-negative) neurons in the striatum. ppEnk is used as a marker of D2R-positive neurons. (B) Inflammatory aversion is blocked in mice lacking EP1Rs $(n=10)$ compared with controls $(n=5)$ but rescued to a normal level when EP1Rs are reexpressed in D1R-expressing neurons $(n=7)$. (C) Conditioning with microinjections of $\mathrm{NaCl}$ in either caudate putamen (CPu) or nucleus accumbens (NAc) ( $n=7)$ or PGE in the NAc ( $n=4)$ or $\mathrm{CPu}(n=4)$. PGE $\mathrm{F}_{2}$ injected into the dorsal striatum induced aversion, whereas the other injections did not. (D) Plot of approximate microinjection sites for the injections made with PGE in C. (E and F) PGE levels in the dorsal striatum ( $n=7, \mathrm{NaCl} ; 8, \mathrm{LPS})$ and the nucleus accumbens ( $n=7, \mathrm{NaCl} ; 10, \mathrm{LPS})$ after injections of $\mathrm{NaCl}$ or LPS i.p. (G) PGE levels in the CPu after a single LPS injection in mice lacking COX-1 ( $n=4, \mathrm{NaCl}$; 8 , LPS). (H) Representative injection site of viral vectors expressing Cre recombinase in the striatum (CPu), not affecting the cerebral cortex (Ctx). A Cre-dependent reporter virus, expressing EGFP upon recombination, was coinjected with the Cre virus. (I) Aversion scores in control mice and mice with a rescue of EP1Rs in the striatum ( $n=5$ and 5 , respectively). Both groups were injected with Cre-expressing viral vectors. Scale bars: $25 \mu \mathrm{m}(\mathbf{A})$ and $200 \mu \mathrm{m}$ (H). ${ }^{*} P<0.05$, ${ }^{*} P<0.01$, ANOVA followed by Bonferroni's (B) or Dunnet's (C) post hoc test, or Student's $t$ test (E-G and I).

JCI83844DS1). Mice from this line were crossed to mice with an inducible Cre recombinase expressed selectively in dopamine D1R-expressing neurons. We validated the specificity of the Cre line to D1R-expressing neurons by demonstrating robust recombination in medium spiny neurons in the striatum that were negative for preproenkephalin, a marker of D2R neurons (Figure 4A). Mice deficient in EP1Rs demonstrated no aversion (Figure 4B). In contrast, mice with EP1R expression selectively rescued in D1R neurons displayed an intact avoidance behavior (Figure 4B). This result demonstrates that inflammation causes aversion and discomfort by PG-mediated modulation of D1R-expressing cells. Although D1Rs are most strongly expressed in the striatum, they are also expressed in other structures. To determine the site of inflammation-induced $\mathrm{PGE}_{2}$ triggering aversion, we injected a low dose (200 picomole) of $\mathrm{PGE}_{2}$ into the nucleus accumbens or the dorsal striatum and examined whether it induced aversion. $\mathrm{PGE}_{2}$ injection into the dorsal striatum induced robust place aversion, whereas injections in the nucleus accumbens did not (Figure 4, $\mathrm{C}$ and $\mathrm{D})$. We next measured $\mathrm{PGE}_{2}$ levels in the dorsal striatum, the surrounding cortex, and the nucleus accumbens in mice given saline or LPS. PGE $_{2}$ levels were significantly elevated in the dorsal striatum in response to inflammation (Figure 4E), whereas there was only a tendency toward an increase in the cortex (Supplemental Figure 2). There occurred no induction of $\mathrm{PGE}_{2}$ in the nucleus accumbens upon LPS stimulation (Figure 4F). Mice lacking COX-1 did not display any inflammation-induced increase in $\mathrm{PGE}_{2}$ in the dorsal striatum (Figure $4 \mathrm{G}$ ). To further demonstrate that the stria- tum is the critical area of PG action, we tested if rescue of EP1R expression selectively in the striatum would rescue the aversion induced by LPS. We injected adeno-associated virus 5 (AAV5) vectors expressing Cre recombinase and a Cre-dependent reporter construct bilaterally into the striatum of WT mice and mice from the mouse line in which EP1 expression can be restored by Cre activity (Figure $4 \mathrm{H}$ ). Indeed, local rescue of EP1R expression in the striatum restored the LPS-induced aversion to levels similar to those in normal mice injected with the same viral vector (Figure 4I). These findings demonstrate that EP1R expression in the striatum is critical for inflammation-induced aversion.

Inflammatory aversion is induced by inhibition of dopamine signaling. The activation of EP1Rs on striato-nigral D1R-expressing neurons inhibits dopaminergic neurons through GABA release (25). Therefore, we next tested whether the GABA-mediated inhibition of dopaminergic cells is involved in inflammatory aversion by using a mouse line in which Cre activity specific to dopaminergic cells can be induced in adult animals (Dat Cre-ER $R^{T 2}$ ) (26). We validated the specificity of the recombination induced by the Dat Cre-ER $R^{T 2}$ line by crossing it with a reporter line (Figure $5, \mathrm{~A}$ and $\mathrm{B}$ ). Subsequently, we crossed Dat Cre-ER ${ }^{T 2}$ mice with mice in which the gene encoding the GABAA receptor subunit $\gamma 2$ was floxed, hence generating mice lacking this subunit selectively in dopaminergic cells (Gabrg2 Dat Cre-ER ${ }^{T 2}$ ). These mice appeared normal and displayed normal locomotor activity (Supplemental Figure 3). When tested for inflammation-induced aversion, Gabrg2 Dat $C r e-E R^{T 2}$ mice displayed no avoidance of the inflammation-paired 

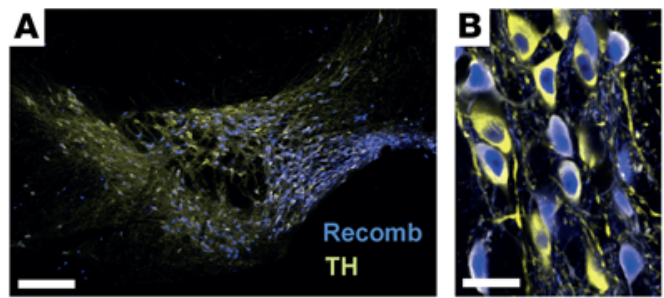

C
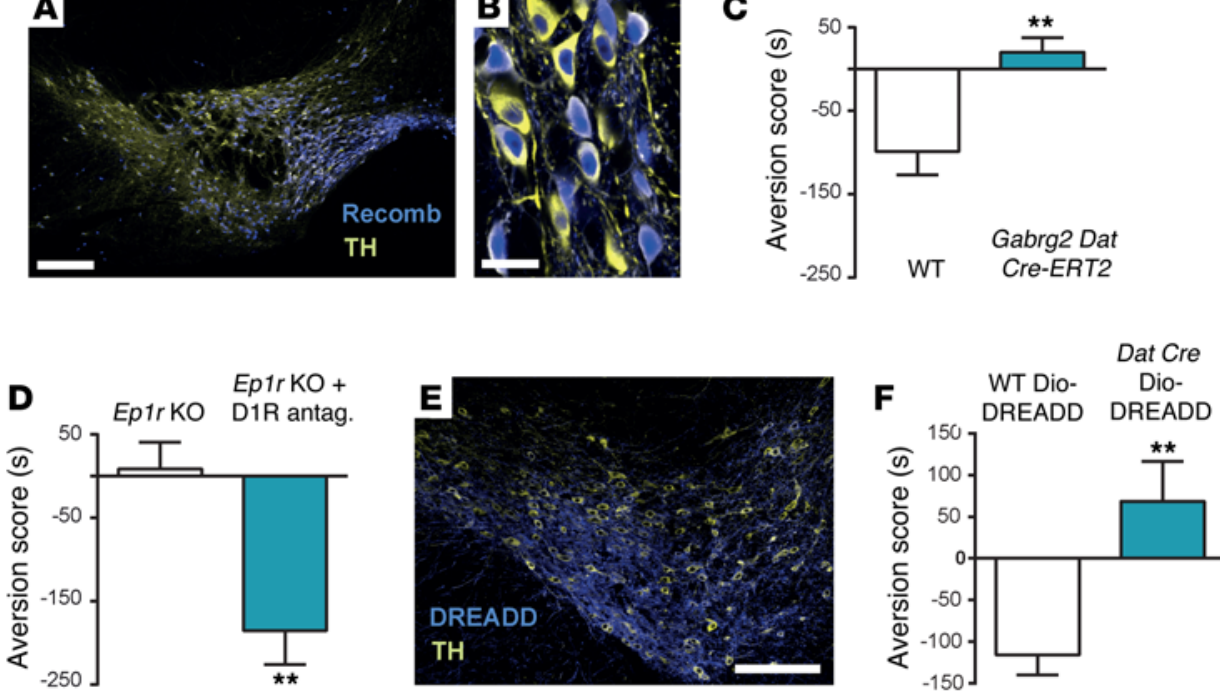

Figure 5. Inflammation induces aversion by inhibiting dopaminergic signaling. (A and $\mathbf{B}$ ) Recombination induced by the Dat Cre-ER $R^{T 2}$ line. Recombination is specific to tyrosine hydroxylase-positive (TH-positive) dopaminergic cells. (C) Inflammatory aversion is blocked in mice lacking GABAA receptor $\gamma 2$ subunits (Gabrg2 Dat Cre-ER ${ }^{T 2} ; n=7, \mathrm{WT} ; 7$, Gabrg2 Dat Cre-ER ${ }^{T 2}$ ). (D) Ep1r KO mice do not display inflammationinduced aversion but develop place avoidance if a D1R antagonist is administered i.p. prior to LPS training ( $n=6$, Ep1r KO; 5, Ep1r KO + D1R antagonist). (E) DREADD-Gq expression in the midbrain of Dat Cre-ER ${ }^{\text {T2 }}$ mice (immunofluorescent detection of mCherry fused to the receptors). (F) Aversion scores in WT and Dat Cre-ER ${ }^{T 2}$ mice injected with a Cre-dependent Gq-DREADD-expressing viral vector and injected i.p. with CNO before LPS training ( $n=7$, WT; 5, Dat Cre Dio-DREADD). Scale bars: $200 \mu \mathrm{m}$ (A and E) and $25 \mu \mathrm{m}$ (B).

${ }^{* *} P<0.01$, Student's $t$ test.

chamber (Figure 5C). The absence of LPS-induced CPA in Gabrg2 Dat Cre-ER ${ }^{T 2}$ mice supports the hypothesis that EP1R activation on D1R-expressing neurons triggers aversion through the GABAA receptor-mediated inhibition of dopaminergic cells. Therefore, to provide further evidence that the inflammation-induced aversion is due to the inhibition of dopaminergic transmission, we treated mice lacking EP1 with saline or a D1R-antagonist (SCH23390; 0.2 $\mathrm{mg} / \mathrm{kg}$ ) prior to the injection of LPS. Mice lacking EP1 again displayed no LPS-induced aversion, but addition of the D1R antagonist restored the aversion in Ep1r KO mice (Figure 5D). The dose of D1R-antagonist used was not aversive in WT mice but potentiated LPS-induced aversion (Supplemental Figure 4). However, this potentiation was much smaller than the proaversive effect it had in LPS-treated Ep1r KO mice. To investigate if positive modulation of dopaminergic neurons could abolish the aversion induced by LPS, we used a chemogenetic approach. Dat Cre-ER $R^{T 2}$ mice were injected with viral vectors (AAV8) inducing Cre-dependent expression of hM3Dq, a Gq-coupled designer receptor exclusively activated by a designer drug (DREADD), in the ventral midbrain. After induction of Cre activity, we detected expression of the construct selectively in processes of midbrain dopaminergic cells of Dat Cre-ER $R^{T 2}$ mice (Figure 5E). Mice with hM3Dq expression in midbrain dopaminergic cells and WT mice injected with the same vector were given the designer drug CNO $(2 \mathrm{mg} / \mathrm{kg})$ during the LPS sessions. This positive modulation of the dopaminergic cells completely abolished the aversion in the hM3Dq-expressing mice, whereas WT mice injected with the vector showed normal aversions to LPS (Figure 5F). Collectively, these findings strongly sug( 2 sessions with 1 injection in each hind paw). Conditioned place aversion to formalin-pain is a well-established model for the study of the affective component of persistent pain. In contrast to the case after LPS injections, Myd88 $\Delta$ bEnd and Gabrg2 Dat Cre-ER $R^{T 2}$ mice displayed intact avoidance behaviors toward the pain-paired chamber, and Ep1r KO mice and mice in which EP1R was reintroduced specifically on D1R-positive neurons displayed similar aversive reactions (Figure 6, E-G). These results demonstrate several things. First, they demonstrate that the mouse lines tested for pain-induced aversion are capable of learning and expressing an aversive response. Thus, the fact that they do not display inflammation-induced aversion is not due to general deficits in memory or locomotor behavior. Secondly, since LPS-induced aversion is blocked in several mouse lines having intact pain-induced aversion, it is unlikely that local pain or general hyperalgesia contribute to the LPS-induced aversion. Finally, the findings show that the pathway identified in this study does not play a general role in all kinds of aversion but that it instead is likely to be specific for systemic inflammation.

\section{Discussion}

Here, we identify a pathway through which peripheral inflammatory processes can signal brain circuits controlling motivation and induce malaise and aversion. This pathway involves the activation of the brain endothelium, COX-1-mediated cerebral $\mathrm{PGE}_{2}$ production, and PG EP1R-mediated modulation of dopaminergic circuits (Figure 6H). We demonstrate that the interventions blocking aversion had no effect on immune-induced loss of appetite. From pre- 

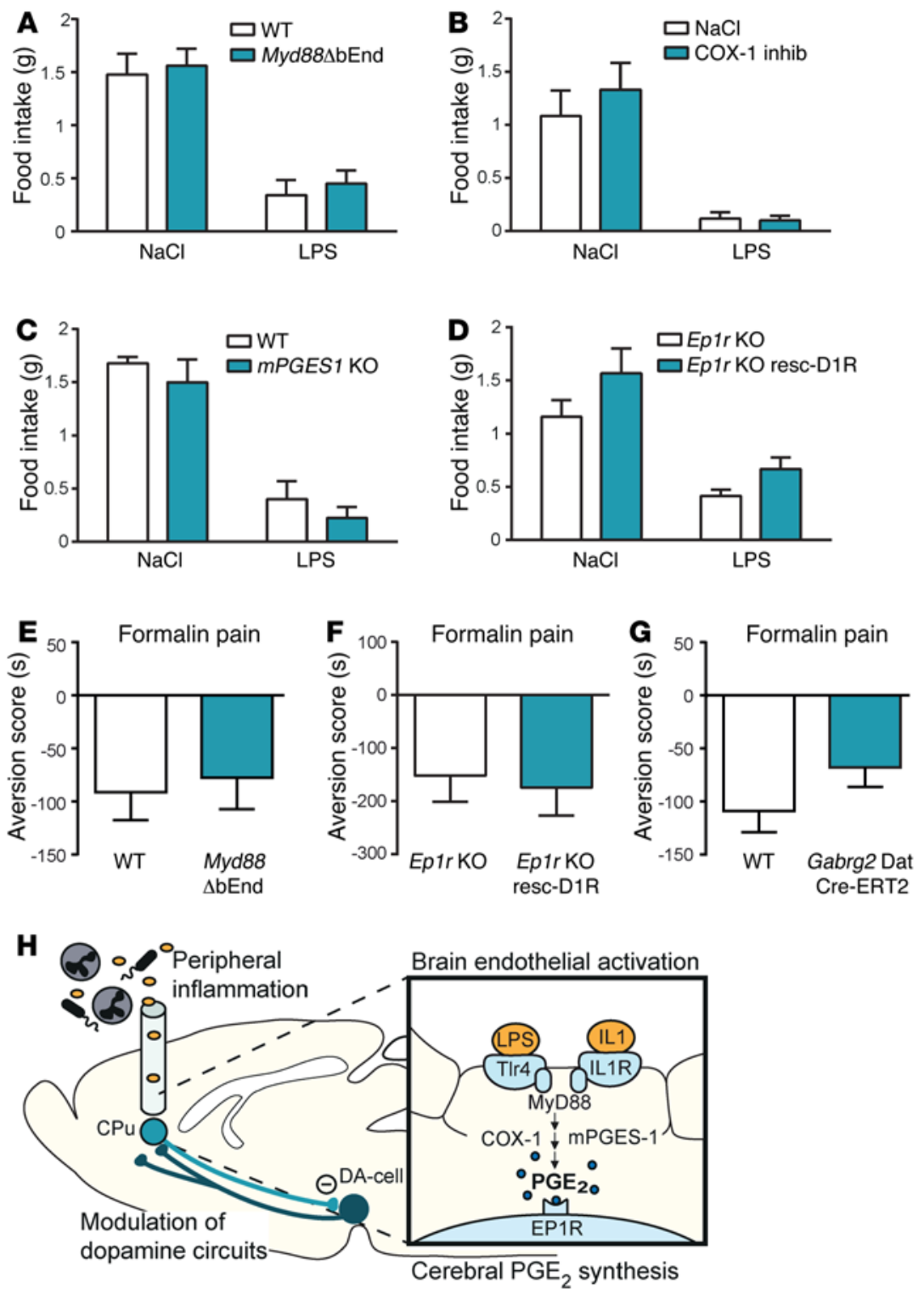

vious studies, we also know that fever is mediated by COX-2 and EP3Rs rather than COX-1 and EP1Rs $(1,27,28)$. Thus, the pathway triggering inflammation-induced aversion is distinct from those mediating other inflammatory symptoms, although it has some similarities to the pathway mediating rapid corticosterone release $(21,29,30)$. In line with previous findings $(31,32)$, these results demonstrate that the different central nervous symptoms of systemic inflammation are induced by selective routes from an early point in the signaling chain. This, in turn, likely reflects that it has been of adaptive value to mount sickness syndromes with different relative weights on individual symptoms in response to different types of immune challenge. The differences between the pathway triggering aversion and the pathways triggering other inflammatory symptoms also demonstrate that malaise and aversion are not simply indirect effects of fever, loss of appetite, or pain but that they instead constitute an independent inflammatory symptom. The mechanistic differences between the pathways generating different inflammatory symptoms provide possibilities
Figure 6. Inflammatory aversion is induced by mechanisms different from those triggering inflammatory loss of appetite. (A-D) Food intake $0-6$ hours after injection of $\mathrm{NaCl}$ or LPS $(10 \mu \mathrm{g} / \mathrm{kg}$, i.p.) in WT mice and mice lacking MyD88 in endothelial cells (Myd88 $\Delta$ bEnd), mice given the COX-1 inhibitor SC-560, mice lacking mPGES-1, mice lacking EP1Rs, and mice lacking EP1Rs except in D1R-expressing cells $(n=4-9$ in each group). (E-C) Aversion scores in response to formalin pain in Myd88 $\Delta$ bEnd mice (E; $n=10$, WT; 12, Myd88 8 bEnd), in mice lacking EP1Rs, and mice lacking EP1Rs but with reexpression in D1R expressing neurons ( $F ; n=6, E p 1 r \mathrm{KO} ; 6, E p 1 r \mathrm{KO}$ resc-D1R) and in Gabrg2 Dat Cre-ER ${ }^{T 2}$ mice (G; $n=7$, WT; 5, Gabrg2 Dat Cre-ER ${ }^{T 2}$ ). (H) Summary of the mechanism proposed to underpin inflammation-induced aversion. Two-way ANOVA (A-D) or Student's $t$ test (E-G).

for the development of symptom-specific therapies. For example, with EP1 antagonism, fever (1) and anorexia should remain, which in some cases might be beneficial (33), but malaise and feelings of discomfort should be blocked.

Our findings highlight the importance of the brain endothelium as a signaling interface between the circulation and the brain. The results suggest that the endothelial cells can directly detect both IL-1 and LPS (or another TLR4 ligand) in the circulation and transmit that signal further to motivational circuits. For fever, $\mathrm{PGE}_{2}$ is the critical endothelium-derived messenger (16), and since inflammatory aversion is also $\mathrm{PGE}_{2}$ dependent, it is not unlikely that endothelial $\mathrm{PGE}_{2}$ is involved. Brain endothelial cells express COX-1, and this expression has been suggested to drive the early phase of corticosterone release (29). However, the strongest cerebral COX-1 expression is seen in microglia, and the $\mathrm{PGE}_{2}$ synthesis in response to social defeat has been suggested to be of microglial origin (24). Thus, LPS-induced activation of the brain endothelium could indirectly induce COX-1 activity in microglia in our model. Future studies using cell type-specific deletions of COX-1 will be necessary to define the respective roles of endothelial and microglial COX-1 in inflammation-induced aversion. It is likely that PGs from different sources induce aversion under different phases of inflammation. While we show that COX-1 is critical for the aversive response in the early phase of an inflammation, COX-2-derived $\mathrm{PGE}_{2}$ might be important for aversion and depressive symptoms in response to chronic inflammation. There are also other molecular systems involved in behavioral changes induced by inflammation. For example, brain cytokines and indoleamine 2,3 dioxygenase metabolites have been shown to induce behavioral changes in response to inflammation $(6,34,35)$. How these systems interact with the pathway identified here is currently not clear.

The finding that the EP1R is critical for inflammationinduced aversion is in agreement with with previous studies demonstrating an involvement of EP1Rs in affective functions in 
the noninflamed state. EP1Rs control impulsive behavior under stress (36), augment some effects of cocaine (23), and are protective against the development of social avoidance in response to repeated social defeat (24). This EP1R-driven social avoidance is also mediated by COX- 1 and has been suggested to depend on the inhibition of dopaminergic cells, as the activation of EP1Rs on D1R neurons leads to increased GABAergic inhibitory input onto dopaminergic cells (25). In light of these studies, it is likely that the aversion seen in the present study is driven by a decreased firing rate of midbrain dopaminergic neurons. In line with this evidence, LPS injection leads to a persistent reduction in the firing rate of dopaminergic cells (37). A decrease in firing rate of dopaminergic cells is sufficient to cause aversion, as demonstrated with optogenetic manipulation $(38,39)$. However, different subsets of dopaminergic cells signal rewarding and aversive events through specific neural pathways (40-43). Thus, the impact of EP1R signaling on the mesolimbic dopaminergic system could be complex and multifaceted. Our findings also demonstrate that neurons in the dorsal striatum, rather than in the nucleus accumbens, are the targets of aversion-inducing $\mathrm{PGE}_{2}$. This result was somewhat surprising, given the central role of the nucleus accumbens in reward processing, but the dorsal striatum is also important for aversion and reward (44). In addition, the EP1R-mediated effects on striatal function have primarily been shown in striatal neurons projecting to the substantia nigra (25). Our findings indicate that EP2Rs are also involved in the signaling of inflammation-induced aversion. EP2Rs are not expressed to any higher extent in the striatum (45), indicating that their role is different from that of EP1Rs. Since the aversion is blocked in both EP1R and EP2R mutants, it is likely that they are parts of parallel pathways, both necessary for inflammation-induced aversion.

The striking similarities between the pathway described here (Figure $6 \mathrm{H}$ ) and the pathway mediating social avoidance in response to stress are interesting in light of the studies demonstrating interactions between social and immunological stress responses. Social stress induces inflammatory responses in humans $(46,47)$, PG synthesis inhibition reduces the distress caused by social rejection (48), and inflammation is a critical mediator in the pathophysiology of psychiatric disorders, such as depression $(4,6-8,49)$. Collectively, these data indicate that chronic, mild inflammation and social stress may induce a negative mood by synergistic effects on PG signaling onto dopamine circuits. Whereas we examined how mild acute inflammation induces discomfort and negative affect, others have studied the mechanisms behind inflammation-induced despair-like behavior in rodents using the forced-swim tests or tail-suspension tests $(6,34,50)$. Findings from such studies suggest that despair-like behavior is also PG dependent (51), but they have otherwise tested the components of the signaling pathway identified here to a very limited extent. It should also be noted that we used a dose of LPS that is $80-250$ times lower than those typically used to induce despair-like behavior $(6,50)$, and it is conceivable that different strength of the inflammatory challenge activates distinct signaling pathways and neural circuits. In this context, the low dose used in the present study may represent an advantage, since the systemic immune activations seen during chronic inflammatory disease or major depression are mild compared with the strong activation employed in previous models using LPS administration to rodents. Our analysis was performed in the mouse, but similar circuits are likely important for the inflammatory regulation of affective states in humans. For example, chronic peripheral IFN- $\alpha$ exposure reduces striatal dopamine (DA) release in nonhuman primates (52), and human imaging studies have demonstrated that interferon- $\alpha$ therapy (53), LPS administration (11), and the acute, low-grade inflammation induced by typhoid vaccine (54) all lead to activity changes in the basal ganglia and that dopamine is important for such changes (55).

In conclusion, we describe a pathway by which inflammatory signals can access the motivational neurocircuitry and induce a negative affective state. The inhibition of the described pathway might explain how COX inhibitors make you feel better during a flu or common cold and could be a relevant strategy for the alleviation of depressive symptoms associated with inflammatory diseases.

\section{Methods}

Animals. The animals were single-housed for a minimum of 48 hours prior to the experiments and kept in a pathogen-free facility on a regular 12-hour light/dark cycle. For behavioral experiments, only male mice were used, whereas both sexes were used in biochemical and food-intake experiments. All mice were more than 6 weeks old at the onset of experiments, and the typical age was 8-20 weeks. Food and water were provided ad libitum, and all experiments were performed during the active phase, unless otherwise noted. Tlr $4^{f l / f l}$, Slco1c1 Cre$E R^{T 2}, \operatorname{Cox} 1 \mathrm{KO}, \operatorname{Cox} 2 \mathrm{KO}, m P G E S 1 \mathrm{KO}$, Ep1r KO, Ep3r KO, Ep $4 r^{f / f l}$, Drd1 $C r e-E R^{T 2}$, and Dat Cre-ER ${ }^{T 2}$ mice have been previously described in the literature $(14,26,56-63)$. Cre-recombinase activity was induced by administering tamoxifen dissolved in sunflower seed oil/alcohol mixture 10:1. The mixture was i.p. injected at $1 \mathrm{mg}$ per mouse twice a day

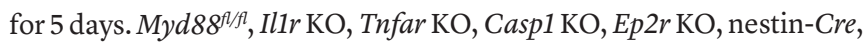
Gabrg $2^{f l f l}$, LysM-Cre, tdTomato-reporter, i.c.v. cannulated C57BL/6J, and WT C57BL/6J mice were all purchased from The Jackson Laboratory. The mice had a C57BL/6 background, with exception of Cox1 (B6;129P2), Cox2 (B6;129P2), and Gabrg2 $2^{f / f l}$ (129X1/SvJ).

Generation and characterization of mice with conditional reactivation of EP1R expression. EP1R-null animals were generated by insertion of a loxP-flanked transcriptional blocking cassette (TBC) into the Ptger1 locus. The targeting construct was generated using ET cloning and related technologies within EL250 cells $(64,65)$, and its assembly involved linking the following DNA segments: a splice acceptor site from the mouse engrailed-like gene En-2 followed by an SV40 poly(A) signal, which was derived from the BamHI fragment of pGT1.8geo plasmid (provided by J. Rossant, Mount Sinai Hospital, Toronto, Ontario, Canada); an SV40 enhancer followed by a neomycin/kanamycin resistance gene and 2 HSV-TK poly(A) signals, which was derived from the pSV-Cre plasmid (provided by F. Stewart, European Molecular Biology Laboratory [EMBL] Heidelberg, Heidelberg, Germany); a synthetic poly(A) signal/transcriptional pause signal, taken from the pGL3-control vector (Promega); and a second synthetic poly(A) signal followed by the intergenic sequence between human complement genes C2 and Factor B, which contains a Myc-associated zinc finger protein (MAZ) binding site and which was derived from plasmid pHR68MAZ (provided by Barry Rosen, Wellcome Trust Sanger Institute, Cambridge, United Kingdom). loxP sites were added to flank the TBC, which next was inserted into a mouse Ptger1-containing bacterial 
artificial chromosome (RPCI.22 39 L7; BACPAC Resources Center at Children's Hospital Oakland Research Institute, Oakland, California, USA), at an insertion site located 497 bp upstream of the EP1R start codon (within a 962-bp putative intron downstream of the proposed EP1R transcriptional start site). The final targeting construct, which consisted of the loxP-flanked TBC flanked by 4.0-kb EP1R homology arms, was electroporated into J1 embryonic stem cells (ESCs) provided by E. Li, A. Sharp, and R. Jaenisch, and correct targeting was confirmed by Southern blot and PCR analyses. After germline transmission was established, the chimera carrying the recombinant allele was crossed onto a C57BL/6J background, and thus, all mice were on a mixed C57Bl6/J and 129Sv background. Offspring were genotyped by PCR using the primers 5'-GTCTGTGGGGACAGAGAGGA-3' and 5'-GTATCTGCTGGGGGTCTTGA-3' flanking the insertion site in intron 1, as well as the primer $5^{\prime}$-GGGAGGTGTGGGAGGTTTT-3' specific for the TBC. Mice with this genetic modification were crossed with mice expressing an inducible Cre selectively in dopamine D1Rpositive neurons. This resulted in mice with EP1Rs expressed only in cells expressing the dopamine D1R.

Virus generation. The viral vectors used for Cre-induced rescue of EP1Rs were pseudotyped AAV2/5. Transgene expression was driven by a neuron-specific human synapsin promoter. The GFP vector contained a FLEX cassette (66) resulting in Cre-dependent expression. The AAV vectors were produced using a double-transfection method with the appropriate transfer plasmid and the helper plasmid containing the essential adenoviral packaging genes, as described previously (67). Vectors were purified by iodixanol step gradients and Q Sepharose column chromatography (Sigma-Aldrich). The purified viral vector suspension was titrated with TaqMan quantitative PCR (qPCR) and primers targeting the woodchuck hepatitis virus posttranscriptional regulatory element (WPRE) sequence. The final titers of the injected $\mathrm{AAV}$ were in the range of $2 \times 10^{14}$ to $3 \times 10^{14}$ genome copies $/ \mathrm{ml}$. rAAV8hSyn-DIO-hM3D(Gq)-mCherry for Dat Cre-ER ${ }^{T 2}$-dependent chemogenetic activation of neurons was obtained from the Vector Core at University of North Carolina, Chapel Hills, North Carolina, USA.

In situ hybridization. EP1R expression was monitored by using a ${ }^{35} \mathrm{~S}$-labeled riboprobe against exons 2 and 3 generated from a DNA template containing a 718-base pair SmaI-PstI fragment of a functional cDNA encoding the mouse EP1R (GenBank database accession number NM_013641). Plasmids were linearized and transcribed with $\mathrm{T} 3$ polymerases to produce antisense RNA probes that were ${ }^{35} \mathrm{~S}$-radiolabeled. Sections were mounted and hybridization was performed as previously described (68). Probes were visualized by dipping the slides in photographic emulsion, allowing 2-4 weeks for exposure, and then developing the slides in Kodak D-19. Slides were fixed, dried, and coverslipped.

IHC. Brains were collected after intracardial perfusion with saline and $4 \%$ paraformaldehyde (PFA) in PBS ( $\mathrm{pH}$ 7.4). The brains were postfixed for 4 hours in $4 \%$ PFA and subsequently cryoprotected in $30 \%$ sucrose PBS solution overnight. Coronal sections $(40 \mu \mathrm{m})$ were cut on freezing microtome or cryostat, collected in cold cryoprotectant buffer (0.1 M phosphate buffer, 30\% ethylene glycol, 20\% glycerol), and stored at $-20^{\circ} \mathrm{C}$ until further use. For immunofluorescent labeling, free-floating sections were washed in PBS, incubated in blocking solution (1\% BSA and $0.3 \%$ Triton X-100 in PBS), and subsequently incubated with primary antibody (rat anti-PECAM1 [CD31], 1:1,000 [AbD Serotec]; rabbit anti-preproEnkephalin, 1:1,000 [Neuromics]; rabbit anti-red fluorescent protein [RFP], 1:1,000 [MBL International]; or mouse anti-tyrosine hydroxylase, 1:1,000 [ImmunoStar Inc.]) in blocking solution overnight. The following day, the sections were washed and incubated with secondary antibody (AlexaFlour488/568 anti-rat [1:5,000], anti-rabbit [1:1,000], or anti-mouse [1:5,000], all from Invitrogen) in blocking solution for 2 hours. The sections were then washed and mounted on object glasses with gold antifade reagent (Invitrogen). To identify cells expressing tdTomato owing to recombination with either Slco1c1 Cre-ER $R^{T 2}$, Drd1 Cre-ER $R^{T 2}$, or Dat Cre-ER ${ }^{T 2}$, raw tdTomato fluorescence was visualized. Sections were analyzed using a Nikon 80i microscope equipped with epi-fluorescence and a Zeiss Axio Observer Z1 fluorescence microscope connected to a Zeiss LSM 700 confocal unit with 405, 488, 555, and $639 \mathrm{~nm}$ diode lasers.

Drugs and injections. LPS from E. coli (055:B5, Sigma-Aldrich) was administered i.p. at a concentration of $10 \mu \mathrm{g} / \mathrm{kg} 10$ minutes prior to conditioned place aversion training (CPA training) and measurements of locomotor activity, or 1 hour before food-intake measurements. This concentration was also given via i.v. catheters directly before CPA training. IL-1 $\beta$ (PeproTech) was injected i.p. at $600 \mathrm{ng} / \mathrm{mouse}$ directly before CPA training. Diluted formalin $(2.5 \% ; 20 \mu \mathrm{l})$ was injected below the skin on the dorsal side of the hind paw to induce acute inflammatory pain. Indomethacin (Alpharma Inc.) was injected i.p. $0.3 \mathrm{mg} / \mathrm{kg}$ 60 minutes before LPS CPA training or food intake. Parecoxib (Dynastat, Pfizer) was injected i.p. $4 \mathrm{mg} / \mathrm{kg} 30$ minutes prior to CPA training. SC560 (Tocris Bioscience) was injected i.p. $5 \mathrm{mg} / \mathrm{kg}$ (5\% DMSO) 30 minutes before CPA training or food intake. SC560 (1 $\mu \mathrm{g}$ in $1 \mu \mathrm{l})$ was also administered i.c.v. via guide cannula at 30 minutes prior to LPS conditioning. Anakinra (Kineret, Swedish Orphan Biovitrum) $10 \mathrm{mg} / \mathrm{kg}$ i.p. was preadministered 15 minutes before CPA training. $\mathrm{PGE}_{2}$ (Tocris Bioscience) was microinjected via guide cannula into $\mathrm{NAc}$ or $\mathrm{CPu}$ at a concentration of $200 \mathrm{pmol} / \mu \mathrm{l}$. SCH23390 (Tocris Bioscience) was given i.p. $(0.2 \mathrm{mg} / \mathrm{kg}) 15$ minutes prior to CPA training. Clozapine N-oxide (CNO) from Enzo was injected i.p. at $2 \mathrm{mg} / \mathrm{kg}$ 20 minutes before LPS CPA training. All compounds were diluted in physiological saline $(0.9 \% \mathrm{NaCl})$, and i.p. injections were in a volume of $100 \mu \mathrm{l} / 25 \mathrm{~g}$ mouse.

Catheter surgery. Catheterization was performed under anesthesia induced by a mixture of $1 \mathrm{mg} / \mathrm{kg}$ dexmedetomidine and $75 \mathrm{mg} / \mathrm{kg}$ ketamine i.p. using aseptic surgical techniques. Following induction, the mice received i.p. analgesia $(0.1 \mathrm{mg} / \mathrm{kg}$ buprenorphine). A catheter (MIVSA mouse catheter, CamCaths) with a 9.0-cm length of silicone tubing (inner diameter, $0.2 \mathrm{~mm}$; outer diameter, $0.4 \mathrm{~mm}$ ) was inserted $1.2 \mathrm{~cm}$ into the right jugular vein, tunneled s.c. to the ventral aspect of the neck, and anchored to a 26-gauge stainless steel tubing in plastic secured s.c. with a propylene knitted mesh (diameter, 20 $\mathrm{mm})$. Catheter patency was confirmed by backflush, and skin incisions were closed with Prolene 6-0 (Johnson \& Johnson). Anesthesia was reversed with atipamezol $(1 \mathrm{mg} / \mathrm{kg})$ s.c., and the mice were left to recover in a euthermic environment. After surgery, mice were given i.p. analgesic (buprenorphine, $0.1 \mathrm{mg} / \mathrm{kg}$ ) at least every 12th hour for 2 days. Catheters were flushed daily with $100 \mu$ heparin solution (25 $\mathrm{IU} / \mathrm{ml}$ ). Following the CPA test, $100 \mathrm{mg} / \mathrm{kg}$ pentobarbital was used to control for catheter patency and for euthanizing the animals.

Stereotaxic surgery and microinjection. For all stereotaxic surgeries, mice were anesthetized with $5 \%$ isoflurane induction, placed in the stereotaxic frame (Leica Biosystems), and maintained at 1.0\%-1.5\% isoflurane during surgery. 
AAVs were bilaterally injected at $100 \mathrm{nl} / \mathrm{min}$ into either the striatum or midbrain using a gastight Hamilton Neuros syringe (33G). AAV5 (500 nl per injection site) for Cre-dependent expression was delivered in the striatum using stereotaxic coordinates: (anterior/ posterior (AP), +1.1 ; medial/lateral (ML), \pm 1.2 ; dorsal/ventral (DV), -3.0). Midbrain injections of DREADD-Gq virus (600 nl per injection site) were done with stereotaxic coordinates: (AP, $-3.4 ; \mathrm{ML}, \pm 0.48 ; \mathrm{DV}$, -4.6). The injection needle was left in place for 10 minutes after injection to ensure proper diffusion. Induction of Dat Cre-ER ${ }^{T 2}$ was done using tamoxifen 1 week after the viral injections, and the final behavioral tests were conducted 4-6 weeks after the viral injections.

Chronic guide cannulae ( $0.4 \mathrm{~mm}$ in diameter, AgnTho's) for microinjections of $\mathrm{PGE}_{2}$ were implanted using standard aseptic surgical and stereotaxic techniques. The guide cannula was fixed to the skull using 2 anchor screws and dental acrylic. A single stainless steel guide cannula was implanted at the injection site of the right hemisphere: NAc (coordinates from bregma: AP, +1.1; ML, -1.2; and DV, -4.2) and $\mathrm{CPu}(\mathrm{AP},+1.1 ; \mathrm{ML},-1.2 ; \mathrm{DV},-2.8)$. Dummy cannulae extending to the tip of the guide cannulae were inserted until microinjections were performed after a 48 -hour recovery period. In the recovery period, mice were given i.p. analgesic (buprenorphine, $0.1 \mathrm{mg} / \mathrm{kg}$ ). During microinjections, mice were anesthetized with brief $5 \%$ isoflurane induction and kept at $1.0 \%-1.5 \%$ isoflurane during injection. The dummy cannula was removed, and SC560, $\mathrm{PGE}_{2}$, or vehicle (saline) was injected using a microinjection cannula. The solution was injected over a 1-minute period ( $1 \mu \mathrm{l}$ in total). The microinjection cannula remained in place for 2 minutes after the infusion was finished. Animals were either placed directly in the conditioning chamber or allowed to recover in their home cage before CPA training, dependent on the injection time frame as previously described.

Conditioned place aversion. We used a balanced place conditioning procedure to measure aversion, applying a 3-chambered Panlab Spatial Place Preference Box (Harvard Apparatus). On day 1, during a 15-minute pretest, the individual mouse was allowed to move freely between the chambers of the box. Time spent in each compartment was manually recorded by independent experimenters blinded to genotype and treatment. To ensure explorative behavior during the pretest, each mouse had to cross the corridor, entering the opposing chamber a minimum of 5 times to be included in the experiment. Any animal that spent $>66 \%$ of their time during pretests in either of the conditioning chambers were discarded from the study. Mice were assigned to vehicle- or stimulus-paired compartments in a manner to avoid reinforcing natural bias, i.e., LPS injections were paired with the most preferred chamber identified during pretest. This method has been shown to produce reliable conditioned place responses comparable with other paradigms (69). On day 2, mice were injected with aversive stimuli (LPS i.p., IL-1 $\beta$ i.p., or $\mathrm{PGE}_{2}$ in $\mathrm{CPu}$ or $\mathrm{NAc}$ ) before confinement for 1 hour in 1 side compartment. The following day, the mice were trained to saline i.p. in the opposite chamber. This alternating training procedure was continued for 8 consecutive days, until day 10, when the conditioned place aversion was assessed by allowing the mice to freely explore all compartments of the box for 15 minutes. The aversion score was calculated by subtracting the time the mouse spent in the stimulus-paired chamber during the posttest from that of the pretest. For the experiments on formalin-induced pain aversion, the training protocol was slightly modified. Here, the training spanned 2 consecutive days, and each day had 2 sessions. In the morning session, mice were briefly anesthetized with isoflurane and confined to the nonpreferred chamber for 60 minutes. In the afternoon, mice were anesthetized with isoflurane, injected with diluted formalin in the dorsal part of the back paw, and confined to the preferred chamber for 60 minutes.

Food intake. Before the experiments, mice were single-housed for at least 7 days. One hour before dark-period onset, food was withdrawn and LPS or saline was injected i.p. At lights out, mice were given free access to a preweighed amount of standard chow, and food intake was measured 6 hours after refeeding.

Locomotion. Mice were injected with either saline or LPS $10 \mathrm{~min}-$ utes prior to placement in a locomotor chamber box $(450$ [W] $\times 450$ [D] $\times 400[\mathrm{H}] \mathrm{mm}$ ) divided in 4 similar compartments (Panlab, Harvard Apparatus). The locomotor activity of 4 mice was monitored simultaneously over 1 hour using EthoVision tracking software (Noldus). Mobility and total distance traveled was used to evaluate the effect of the acute LPS i.p. injection during the timeframe of a CPA conditioning session.

$P G E_{2}$ assay. One hour after LPS or saline i.p. injections, mice were euthanized by asphyxiation with $\mathrm{CO}_{2}$, and brains were extracted. A coronal section of $2 \mathrm{~mm}$ posterior to the olfactory bulb was extracted using a brain matrix in ice cold PBS, and the tissue was immediately dissected according to specific brain regions and frozen in liquid nitrogen. Nucleus accumbens was removed using a 1-mm sample corer (AgnTho's), the caudate putamen was extracted by needle dissection $(23 \mathrm{G})$, and finally, the cortex was cut off. All tissue samples were stored overnight at $-70^{\circ} \mathrm{C}$. The next day, the sections were homogenized in EDTA-buffer (0.05 M Tris- $\mathrm{HCl}, 0.1 \mathrm{M} \mathrm{NaCl}$, and $0.2 \mathrm{mM}$ ethylene diaminetetraacetate, $\mathrm{pH}$ 7) on frozen blocks using a TissueLyser (QIAGEN) for 2 minutes at $20 \mathrm{~Hz}$. The homogenates (10\% tissue concentration) were then centrifuged at $1,699 \mathrm{~g}$ for 15 minutes at $4^{\circ} \mathrm{C}$ to precipitate membrane debris, and the supernatants were carefully extracted. The content of $\mathrm{PGE}_{2}$ was then determined using a $\mathrm{PGE}_{2}$ EIA kit (Cayman Chemical, 514531) according to the manufacturer's protocol. The content of $\mathrm{PGE}_{2}$ was normalized according to tissue wet weight determined prior to homogenization.

Statistics. Results are illustrated as mean \pm SEM. Statistical comparison of 2 groups was done using Student's unpaired $t$ test. When comparing more than 2 groups with comparable variances, 1-way ANOVA or 2-way ANOVA was done, followed by post hoc analysis with Dunnett's (when comparing many groups to 1 control group) or Bonferroni's (when comparing more than 2 groups to each other) multiple comparison tests to evaluate pairwise group differences. $P<0.05$ was considered statistically significant.

Study approval. All experiments involving the use of animals followed international and national guidelines and were approved by the Research Animal Care and Use Committee in Linköping, Sweden.

\section{Author contributions}

$\mathrm{MF}$, AMK, and DE were responsible for overall study design. MF and AMK performed the behavioral experiments, except for the pain-aversion experiments, which were performed by AKS. Stereotaxic surgeries, viral injections, and microinjections were done by AMK and MF. AN performed the food-intake experiments, and AMK together with $\mathrm{MJ}$ carried out $\mathrm{PGE}_{2}$ measurements. Catheter surgery was implemented and performed by DBW. The histological analysis was done by AMK, JZ, and AL. ML and CBS generated and characterized the EP1R rescue line and wrote corresponding parts of the manuscript. GS and JRP provided the D1 Cre-ERT2 
mice. TRB, DJH, and CPS provided the Tlr $4^{f l / f l}$ mice, and MDB provided the $E p 4 r^{f / f l}$ mice. MS provided the Slcolc1 Cre-ERT2 mice. JJ provided viral vectors and input on how to use them. MJ and UÖK performed the majority of work related to genotyping and colony maintenance. $\mathrm{AB}$ provided several of the mouse lines and input on the design of the study. The main part of the manuscript was written by MF, AMK, and DE. All authors discussed the results and commented on the manuscript.

\section{Acknowledgments}

This study was supported by the European Research Council (ERC-starting grant to D. Engblom), the Swedish Medical Research Council (to D. Engblom and A. Blomqvist), the Knut and Alice Wal- lenberg foundation (to D. Engblom), the Swedish Brain Foundation (to D. Engblom), the County Council of Östergötland (to D. Engblom and A. Blomqvist), and the Swedish Cancer Foundation (to A. Blomqvist). The $E P 4 R^{f / f l}$ mice were generated with support from a Veterans Administration Merit award to M.D. Breyer, and the EP1 conditional mice were generated with support of NIH grants: NS33987 and NS72337 to C.B. Saper. We thank Johanna Karlsson for technical assistance and Åsa Mackenzie, Marie Carlén, and Konstantinos Meletis for input on viral injection techniques.

Address correspondence to: David Engblom, Department of Clinical and Experimental Medicine, Linköping University, 58185 Linköping, Sweden. Phone: 46.101038448; E-mail: david.engblom@liu.se.
1. Saper CB, Romanovsky AA, Scammell TE. Neural circuitry engaged by prostaglandins during the sickness syndrome. Nat Neurosci. 2012;15(8):1088-1095.

2. Dantzer R. Cytokine-induced sickness behavior: where do we stand? Brain Behav Immun. 2001;15(1):7-24.

3. Matcham F, Rayner L, Steer S, Hotopf M. The prevalence of depression in rheumatoid arthritis: a systematic review and meta-analysis. Rheumatology. 2013;52(12):2136-2148.

4. Haroon E, Raison CL, Miller AH. Psychoneuroimmunology meets neuropsychopharmacology: translational implications of the impact of inflammation on behavior. Neuropsychopharmacology. 2012;37(1):137-162.

5. D'Mello C, Swain MG. Liver-brain interactions in inflammatory liver diseases: implications for fatigue and mood disorders. Brain Behav Immun. 2014;35:9-20.

6. Dantzer R, O'Connor JC, Freund GG, Johnson RW, Kelley KW. From inflammation to sickness and depression: when the immune system subjugates the brain. Nat Rev Neurosci. 2008;9(1):46-56.

7. Licinio J, Wong ML. The role of inflammatory mediators in the biology of major depression: central nervous system cytokines modulate the biological substrate of depressive symptoms, regulate stress-responsive systems, and contribute to neurotoxicity and neuroprotection. $\mathrm{Mol}$ Psychiatry. 1999;4(4):317-327.

8. Kivimaki M, et al. Long-term inflammation increases risk of common mental disorder: a cohort study. Mol Psychiatry. 2014;19(2):149-150.

9. Mormede C, Castanon N, Medina C, Dantzer R. Conditioned place aversion with interleukin- $1 \beta$ in mice is not associated with activation of the cytokine network. Brain Behav Immun. 2003;17(2):110-120.

10. Reichenberg A, et al. Cytokine-associated emotional and cognitive disturbances in humans. Arch Gen Psychiatry. 2001;58(5):445-452.

11. Eisenberger NI, Berkman ET, Inagaki TK, Rameson LT, Mashal NM, Irwin MR. Inflammationinduced anhedonia: endotoxin reduces ventral striatum responses to reward. Biol Psychiatry. 2010;68(8):748-754.

12. Johansen JP, Fields HL, Manning BH. The affective component of pain in rodents: direct evidence for a contribution of the anterior cingulate cortex. Proc Natl Acad Sci U S A. 2001;98(14):8077-8082.

13. Licinio J, Wong ML. Pathways and mechanisms for cytokine signaling of the central nervous system. J Clin Invest. 1997;100(12):2941-2947.

14. Ridder DA, et al. TAK1 in brain endothelial cells mediates fever and lethargy. J Exp Med. 2011;208(13):2615-2623.

15. Ching S, et al. Endothelial-specific knockdown of interleukin-1 (IL-1) type 1 receptor differentially alters CNS responses to IL-1 depending on its route of administration. J Neurosci. 2007;27(39):10476-10486.

16. Wilhelms DB, et al. Deletion of prostaglandin E2 synthesizing enzymes in brain endothelial cells attenuates inflammatory fever. J Neurosci. 2014;34(35):11684-11690.

17. Bluthe RM, Laye S, Michaud B, Combe C, Dantzer R, Parnet P. Role of interleukin-1beta and tumour necrosis factor- $\alpha$ in lipopolysaccharide-induced sickness behaviour: a study with interleukin-1 type I receptor-deficient mice. Eur Neurosci. 2000;12(12):4447-4456.

18. Ek M, Engblom D, Saha S, Blomqvist A, Jakobsson PJ, Ericsson-Dahlstrand A. Inflammatory response: pathway across the blood-brain barrier. Nature. 2001;410(6827):430-431.

19. Engblom D, et al. Microsomal prostaglandin E synthase-1 is the central switch during immune-induced pyresis. Nat Neurosci. 2003;6(11):1137-1138.

20. Rivest S. What is the cellular source of prostaglandins in the brain in response to systemic inflammation? Facts and controversies. Mol Psychiatry. 1999;4(6):500-507.

21. Elander L, et al. Inducible prostaglandin E2 synthesis interacts in a temporally supplementary sequence with constitutive prostaglandinsynthesizing enzymes in creating the hypothalamic-pituitary-adrenal axis response to immune challenge. J Neurosci. 2009;29(5):1404-1413.

22. Jakobsson PJ, Thoren S, Morgenstern R, Samuelsson B. Identification of human prostaglandin $\mathrm{E}$ synthase: a microsomal, glutathione-dependent, inducible enzyme, constituting a potential novel drug target. Proc Natl Acad Sci U S A. 1999;96(13):7220-7225.

23. Kitaoka S, et al. Prostaglandin E2 acts on EP1 receptor and amplifies both dopamine D1 and D2 receptor signaling in the striatum. J Neurosci.
2007;27(47):12900-12907.

24. Tanaka K, et al. Prostaglandin E2-mediated attenuation of mesocortical dopaminergic pathway is critical for susceptibility to repeated social defeat stress in mice. J Neurosci. 2012;32(12):4319-4329.

25. Tanaka Y, et al. Prostaglandin E receptor EP1 enhances GABA-mediated inhibition of dopaminergic neurons in the substantia nigra pars compacta and regulates dopamine level in the dorsal striatum. Eur J Neurosci. 2009;30(12):2338-2346.

26. Engblom D, et al. Glutamate receptors on dopamine neurons control the persistence of cocaine seeking. Neuron. 2008;59(3):497-508.

27. Ushikubi F, et al. Impaired febrile response in mice lacking the prostaglandin E receptor subtype EP3. Nature. 1998;395(6699):281-284.

28. Lazarus M, et al. EP3 prostaglandin receptors in the median preoptic nucleus are critical for fever responses. Nat Neurosci. 2007;10(9):1131-1133.

29. Garcia-Bueno B, Serrats J, Sawchenko PE. Cerebrovascular cyclooxygenase-1 expression, regulation, and role in hypothalamic-pituitary-adrenal axis activation by inflammatory stimuli. J Neurosci. 2009;29(41):12970-12981.

30. Matsuoka Y, et al. Impaired adrenocorticotropic hormone response to bacterial endotoxin in mice deficient in prostaglandin E receptor EP1 and EP3 subtypes. Proc Natl Acad Sci U S A. 2003;100(7):4132-4137.

31. Kent S, et al. Different receptor mechanisms mediate the pyrogenic and behavioral effects of interleukin 1. Proc Natl Acad Sci U S A. 1992;89(19):9117-9120.

32. Kent S, Bret-Dibat JL, Kelley KW, Dantzer R. Mechanisms of sickness-induced decreases in food-motivated behavior. Neurosci Biobehav Rev . 1996;20(1):171-175.

33. Harden LM, Kent S, Pittman QJ, Roth J. Fever and sickness behavior: friend or foe? Brain Behav Immun. 2015;50:322-333.

34. O'Connor JC, et al. Lipopolysaccharideinduced depressive-like behavior is mediated by indoleamine 2,3-dioxygenase activation in mice. Mol Psychiatry. 2009;14(5):511-522.

35. McCusker RH, Kelley KW. Immune-neural connections: how the immune system's response to infectious agents influences behavior. J Exp Biol. 2013;216(pt 1):84-98. 
36. Matsuoka Y, et al. Prostaglandin E receptor EP1 controls impulsive behavior under stress. Proc Natl Acad Sci U S A. 2005;102(44):16066-16071.

37. Blednov YA, Benavidez JM, Geil C, Perra S, Morikawa H, Harris RA. Activation of inflammatory signaling by lipopolysaccharide produces a prolonged increase of voluntary alcohol intake in mice. Brain Behav Immun. 2011;25(suppl 1):S92-S105.

38. Tan KR, et al. GABA neurons of the VTA drive conditioned place aversion. Neuron. 2012;73(6):1173-1183.

39. Ilango A, Kesner AJ, Keller KL, Stuber GD, Bonci A, Ikemoto S. Similar roles of substantia nigra and ventral tegmental dopamine neurons in reward and aversion. J Neurosci. 2014;34(3):817-822.

40. Brischoux F, Chakraborty S, Brierley DI, Ungless MA. Phasic excitation of dopamine neurons in ventral VTA by noxious stimuli. Proc Natl Acad Sci US A. 2009;106(12):4894-4899.

41. Lammel S, Ion DI, Roeper J, Malenka RC. Projection-specific modulation of dopamine neuron synapses by aversive and rewarding stimuli. $\mathrm{Neu}$ ron. 2011;70(5):855-862.

42. Lammel S, et al. Input-specific control of reward and aversion in the ventral tegmental area. Nature. 2012;491(7423):212-217.

43. Jeanblanc J, Hoeltzel A, Louilot A. Differential involvement of dopamine in the anterior and posterior parts of the dorsal striatum in latent inhibition. Neuroscience. 2003;118(1):233-241.

44. Kravitz AV, Tye LD, Kreitzer AC. Distinct roles for direct and indirect pathway striatal neurons in reinforcement. Nat Neurosci. 2012;15(6):816-818.

45. Zhang J, Rivest S. Distribution, regulation and colocalization of the genes encoding the EP2and EP4-PGE2 receptors in the rat brain and neuronal responses to systemic inflammation. Eur J Neurosci. 1999;11(8):2651-2668.

46. Bierhaus A, et al. A mechanism converting psychosocial stress into mononuclear cell activation. Proc Natl Acad Sci U S A. 2003;100(4):1920-1925.

47. Steptoe A, Hamer M, Chida Y. The effects of acute psychological stress on circulating inflammatory factors in humans: a review and meta-analysis. Brain Behav Immun. 2007;21(7):901-912.

48. Dewall CN, et al. Acetaminophen reduces social pain: behavioral and neural evidence. Psychol Sci. 2010;21(7):931-937.

49. Felger JC, Miller AH. Cytokine effects on the basal ganglia and dopamine function: the subcortical source of inflammatory malaise. Front Neuroendocrinol. 2012;33(3):315-327.

50. Aguilar-Valles A, Kim J, Jung S, Woodside $\mathrm{B}$, Luheshi GN. Role of brain transmigrating neutrophils in depression-like behavior during systemic infection. Mol Psychiatry. 2014;19(5):599-606.

51. Saleh LA, Hamza M, El Gayar NH, Abd El-Samad AA, Nasr EA, Masoud SI. Ibuprofen suppresses depressive like behavior induced by BCG inoculation in mice: role of nitric oxide and prostaglandin. Pharmacol Biochem Behav. 2014;125:29-39.

52. Felger JC, et al. Chronic interferon-alpha decreases dopamine 2 receptor binding and striatal dopamine release in association with anhedonia-like behavior in nonhuman primates. Neuropsychopharmacology. 2013;38(11):2179-2187.

53. Juengling FD, et al. Prefrontal cortical hypometabolism during low-dose interferon alpha treatment. Psychopharmacology (Berl). 2000;152(4):383-389.

54. Brydon L, Harrison NA, Walker C, Steptoe A, Critchley HD. Peripheral inflammation is associated with altered substantia nigra activity and psychomotor slowing in humans. Biol Psychiatry. 2008;63(11):1022-1029.

55. Capuron L, et al. Dopaminergic mechanisms of reduced basal ganglia responses to hedonic reward during interferon alfa administration. Arch Gen Psychiatry. 2012;69(10):1044-1053.

56. Sodhi CP, et al. Intestinal epithelial Toll-like receptor 4 regulates goblet cell development and is required for necrotizing enterocolitis in mice. Gastroenterology. 2012;143(3):708-718.

57. Morham SG, et al. Prostaglandin synthase 2 gene disruption causes severe renal pathology in the mouse. Cell. 1995;83(3):473-482.
58. Langenbach R, et al. Prostaglandin synthase 1 gene disruption in mice reduces arachidonic acidinduced inflammation and indomethacin-induced gastric ulceration. Cell. 1995;83(3):483-492.

59. Trebino CE, et al. Impaired inflammatory and pain responses in mice lacking an inducible prostaglandin E synthase. Proc Natl Acad Sci U S A. 2003;100(15):9044-9049.

60. Parkitna JR, et al. Loss of the serum response factor in the dopamine system leads to hyperactivity. FASEB J. 2010;24(7):2427-2435.

61. Schneider A, et al. Generation of a conditional allele of the mouse prostaglandin EP4 receptor. Genesis. 2004;40(1):7-14.

62. Fabre JE, et al. Activation of the murine EP3 receptor for PGE2 inhibits cAMP production and promotes platelet aggregation.J Clin Invest. 2001;107(5):603-610.

63. Fleming $\mathrm{EF}$, et al. Urinary concentrating function in mice lacking EP3 receptors for prostaglandin E2. Am J Physiol. 1998;275(6 pt 2):F955-F961.

64. Muyrers JP, Zhang Y, Stewart AF. Techniques: Recombinogenic engineering - new options for cloning and manipulating DNA. Trends Biochem Sci. 2001;26(5):325-331.

65. Lee EC, et al. A highly efficient Escherichia colibased chromosome engineering system adapted for recombinogenic targeting and subcloning of BAC DNA. Genomics. 2001;73(1):56-65.

66. Atasoy D, Aponte Y, Su HH, Sternson SM. A FLEX switch targets Channelrhodopsin-2 to multiple cell types for imaging and long-range circuit mapping. J Neurosci. 2008;28(28):7025-7030.

67. Ulusoy A, Sahin G, Bjorklund T, Aebischer P, Kirik D. Dose optimization for long-term rAAV-mediated RNA interference in the nigrostriatal projection neurons. Mol Ther. 2009;17(9):1574-1584.

68. Gooley JJ, Lu J, Chou TC, Scammell TE, Saper CB. Melanopsin in cells of origin of the retinohypothalamic tract. Nat Neurosci. 2001;4(12):1165.

69. Bardo MT, Rowlett JK, Harris MJ. Conditioned place preference using opiate and stimulant drugs: a meta-analysis. Neurosci Biobehav Rev. 1995;19(1):39-51. 